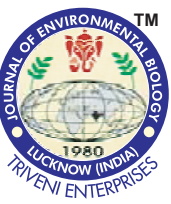

DOI : http://doi.org/10.22438/jeb/39/2/MRN-447

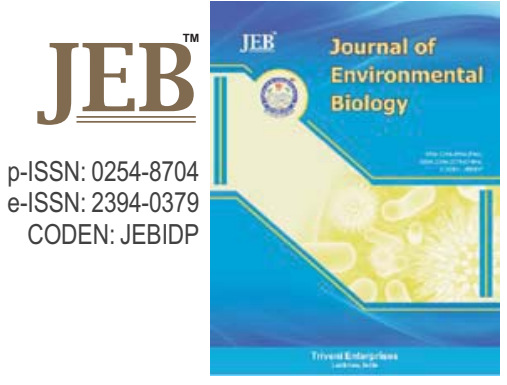

\title{
Immunomodulatory activity of commercial $\beta$-glucan in murine macrophage cell line RAW 264.7
}

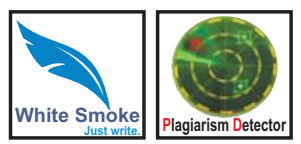

Authors Info

E.Y. Choi', J.Y. Jin', J.Y. Hyeon', S.H. Choe', B.R. Keum', J.M. $\mathrm{Lim}^{2}$, D.C. Park', K.K. Cho ${ }^{3}$ and I.S. Choi ${ }^{1 *}$

1 Department of Life Science, Silla University, Busan, 46958, Republic of Korea

${ }^{2}$ Glucan Corporation, Busan Technopark, Marine Bioindustry Development Center, Busan, 46048, Republic of Korea

${ }^{3}$ Department of Animal Resources Technology, Gyeongnam National University of Science and Technology, Jinju, 52725, Republic of Korea

${ }^{*}$ Corresponding Author Email ischoi@silla.ac.kr

\section{Key words}

$\beta$-glucan

Cytokine

Immunomodulation

Macrophages

Tumor necrosis factor

Publication Info

Paper received : 01.09.2016

Revised received : 23.03.2017

Re-revised received : 08.08.2017

Accepted : 07.09.2017

\begin{abstract}
Aim : $\beta$-glucan, a cell wall component of a variety of fungi, yeasts and bacteria, has a regulatory potential for
\end{abstract} various diseases such as infection and inflammation. The present study investigated the effects of $\beta$-glucan (polycan) on immune modulation in murine macrophage RAW264.7 cells.

Methodology : As immune response parameters, production of nitric oxide (NO), reactive oxygen species (ROS) and cytokines like tumor necrosis factor (TNF)-a, interleukin (IL)-1 13 and IL-6 were assessed. iNOS protein expression, phosphorylation of mitogen-activated protein kinases (MAPKs), degradation of inhibitory $\mathrm{KB}-\mathrm{a}(\mathrm{KKB}-\mathrm{a})$, nuclear translocation of nuclear factor-KB (NF-KB) subunits and phosphorylation of signal transducer and activator of transcription 1 (STAT1) and STAT3 were characterized via immunoblotting.

Results : Production of NO, TNF-a, IL-1 $\beta$ and IL-6 were meaningfully increased in $\beta$-glucan (polycan) treated RAW264.7 cells, along with the increased expression of inducible NO synthase, TNF-a, IL-6 and IL$1 \beta$ mRNA at concentrations with no cytotoxicity. $\beta$-glucan (polycan) treatment also caused the NF-KB and phosphorylation of MAPKs, STAT1 and STAT3, showing $\beta$-glucan (polycan) activated macrophages through activation of NF-KB and MAPKs signaling pathways in RAW264.7 cells.

Interpretation : These results reveal the therapeutic effects of $\beta$-glucan (polycan) may partly be due to its ability to modulate immune functions in macrophages.

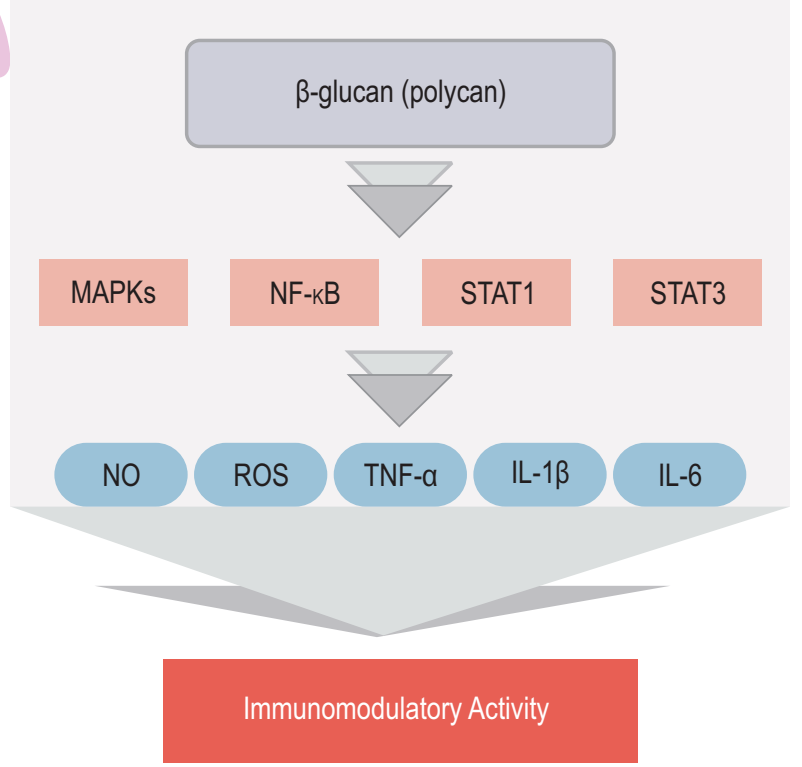




\section{Introduction}

Immuno modulation is stimulation or inhibition of an immune system and activation of immunity by improving an immune system is called "immunity amelioration". This is and essential prevention and treatment strategy to defend human body from various diseases. Among various cells in charge of immune system, macrophage cell is distributed in almost all tissues within a body and plays an important part in an immune reaction that eats and digests foreign substances, wastes or unnecessary cells in the human body (Klimp et al., 2002; Liles, 2001).

Macrophage can stimulate an immune reaction by producing various types of cytokine, like tumor necrosis factor (TNF)- $a$ and interleukin (IL) or NO (nitric oxide) and ROS (reactive oxygen species),through the activities of several signal transfer systems in the cell, such as nuclear factor $\mathrm{KB}$ (NF-kB), phosphoinositide-3-kinase (PI3K)/Akt and mitogenactivated protein kinases (MAPKs) (Murray and Wynn, 2011; Wolf et al., 1994).

Recently, various substances that can improve body defense mechanism are separated from microorganisms, fungus and plants, are drawing huge attention as source resources for immunity enhancement (Kayser et al., 2003; Lee and Hong, 2011). While such new substance have excellent efficacy on the prevention and treatment of various human body diseases, activation of macrophage cell and immune system through modulation of complement system is recognized as the most fundamental process of disease control (Beutler, 2004; Pinto et al., 2007).

B-glucan found inside the cell walls of grains, mushrooms, and yeast is known to powerfully enhance the immunity function inside the body when absorbed in the digestive tract. Also, it effectively inhibits and removes the detrimental microorganisms, viruses, toxins, fungi, etc., through several stimulations. $\beta$-glucan fortifies the action of macrophage cells within the immunity system, making it possible for the macrophage to secrete cytokine, a growth factor of different lymphocytes or leukocytes, strengthening the function of entire immune system. Through this it helps in preventing all kinds of adult diseases and cancer.

The biological actions of these $\beta$-glucan in vivo have been reported to have an anti-tumor cell effect, a defense effect on the invasion of germs, hemato genous function, radio protection effect, wound treatment and improvement effect etc. (Ono et al., 1995; Babineau et al., 1994; Compton et al., 1996). In vitro experiments have also reported that the biological activities of $\beta$ glucan change the form of macrophage cell and affect the occurrence of cytokines such as TNF- $a$, IL- 6 and IL-1, occurrence of nitric oxide and secretion of lysosomal enzyme, of hydrogen peroxide, metabolic action of arachidonic acid, and substitutive course of complement system (Thornton et al., 1996). It has been reported that the mechanism of $\beta$-glucan works by the activity of macrophage cell through a macrophage-specific receptor or by combining with complement system CR3 (Mahauthman et al., 1998). In particular, Aureobasidium pullulans, a black yeast, is broadly used in the industrial production by fermentation (Leathers, 2003). A. pullulans produces receptive $\beta$-glucan that is made up of $\beta$ - $(1,3)$-linked glucose main chain and $\beta$ - $(1,6)$-linked glucose branches outside the cells in some growth conditions (Hamada et al., 2000; Moriya et al., 2013). A. pullulans culture medium possessing $\beta$-glucan as the main ingredient is use das an additional food in numerous nations as it has an immunestimulation activity.

In view of the above, the present study aimed to confirm the effects of $\beta$-glucan (polycan) on immune modulation in RAW264.7 cells and to examine its development possibility as an immunity enhancer.

\section{Materials and Methods}

Cell culture : Murine macrophage cell line RAW264.7 was grown in Dulbecco's transformed Eagle medium that was added to 100

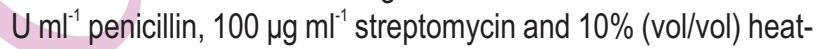
inactivated fetal bovine serum in a humidified compartment with $5 \% \mathrm{CO}_{2} / 95 \%$ air at $37^{\circ} \mathrm{C}$. At confluence, the medium and nonadherent cells were eliminated and exchanged with a fresh culture medium. The cells were distributed to plates at a concentration of $1 \times 10^{6}$ cells $\mathrm{ml}^{-1}$ and were incubated for more than $12 \mathrm{hr}$ to attach the cells onto the plates. The cells were then treated with different doses of $\beta$-glucan for $24 \mathrm{hr}$.

RAW-Blue ${ }^{\mathrm{TM}}$ cells (mouse macrophage reporter cell line, In vitrogen, San Diego, CA) derived from RAW264.7 macro phages were grown in culture medium under the selection of zeocin. The cells stably showed secreted embryonic alkaline phosphatase (SEAP) gene, inducible by NF-KB and AP-1 transcription factors. Upon stimulation, the RAW-Blue ${ }^{\mathrm{TM}}$ cells initiated NF-KB and/or AP-1 followed by secretion of SEAP, which was easily detectable and measurable using QUANTI- Blue $^{\mathrm{TM}}$, a SEAP detection medium (In vivogen).

Estimation of NO production : NO production was assayed by measuring the accumulation of stable oxidative metabolite, nitrite $\left(\mathrm{NO}_{2}\right)$ in culture super natants (Green et al., 1982). Cytotoxicity to murine macrophage cell line RAW264.7 was determined as described by Choi (2014).

Estimation of ROS production: The cells were collected by trypsin-EDTA solution and were washed twice with PBS. They were then incubated with $20 \mathrm{mM} \mathrm{DCFH}-\mathrm{DA}$ for $45 \mathrm{~min}$ at $37^{\circ} \mathrm{C}$ and were immediately subjected to determination of intracellular ROS production, using a flow cytometer through excitation and emission wavelengths of 504 and $529 \mathrm{~nm}$, respectively. Data were processed using a software program. 
A

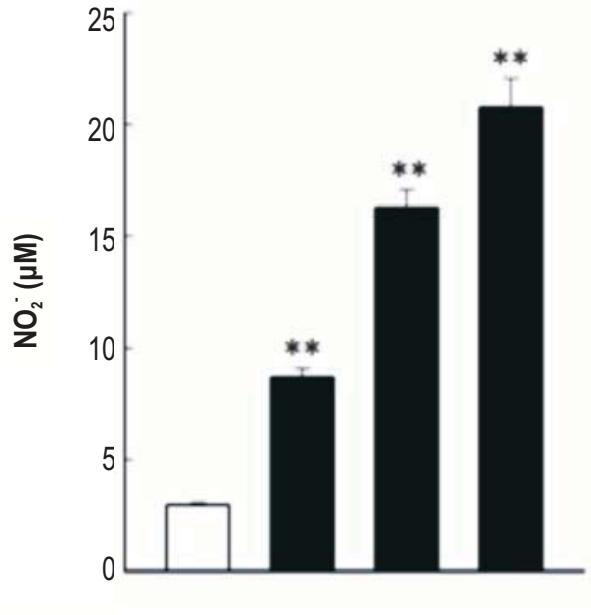

Polycan ( $\mathrm{mg} \mathrm{m}^{-1}$ )

$0.3 \quad 0.75 \quad 1.5$
B

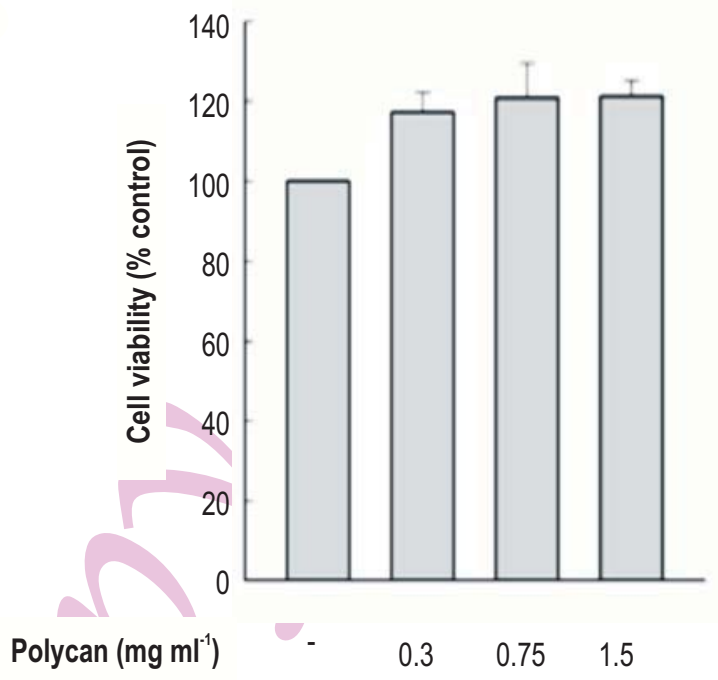

Fig. 1 : Effect of $\beta$-glucan (polycan) on production of $\mathrm{NO}_{2}$ and on viability in RAW264.7 cells. (A) Level of $\mathrm{NO}$ and (B) Cell viability. The results are mean \pm S.E.M. of three independent experiments. ${ }^{*}<0.05$ versus control; ${ }^{* *} P<0.01$ versus control

Estimation of cytokine production : Cells were treated with the different concentrations of $\beta$-glucan for $24 \mathrm{hr}$ (for TNF- $\alpha$ and IL-6) or $48 \mathrm{hr}$ (for IL-1 $\beta$ ), after which the TNF- $\alpha$, IL-1 $\beta$ and IL-6 levels in the culture supernatant were quantified using corresponding enzyme-linked immunosorbent assay (ELISA) kits (Opt EIA; BD Pharmingen, San Diego, CA, USA) according to the manufacturer's instructions.

RNA extraction and Real-time PCR : For division of the entire RNA's in the cells, RNeasy Mini Kit (Qiagen, Valencia, CA, USA) was used by following the manufacturer's guidelines. By using the iScript cDNA Synthesis Kit (BIO-RAD/170-8891), the cDNA was synthesized from the divided RNA, and the real time polymerase chain reaction (PCR) took place by using the Sso Fast Eva Green Super mix (BIO-RAD/172-5201) and thermal cycler (CFX 96 Real Time PCR, Bio-Rad). PCR amplification condition was set to carry out 1 cycle at $98^{\circ} \mathrm{C}$ for $30 \mathrm{sec}$, which led to 45 cycles of the reactions at $95^{\circ} \mathrm{C}$ for $1 \mathrm{sec}$ and $60^{\circ} \mathrm{C}$ for $5 \mathrm{sec}$. $\beta$-actin was used as control. The specific oligonucleotide primer that was designed to amplify cDNA is listed below: iNOS, 5'-CAC GGA GTA GCC TAG TCA A-3' (sense), 5'-CTC TTT CAG GTC ACT TTG GTA G-3' (antisense); TNF-a, 5'-TAG CCA GGA GGG AGA ACA GA-3' (sense), 5'-CAG TGA GTG AAA GGG ACA GA-3' (antisense); IL$1 \beta, 5^{\prime}$-TTC AGG CAG GCA GTA TCA-3' (sense), 5'-AGG ATG GGC TCT TCT TCAA-3' (antisense); IL-6, 5'-GCC AGA GTC CTT CAG AGA GAT ACA G-3' (sense), 5'-GAA TTG GAT GGT CTT GGT CCT TAG C-3' (antisense); $\beta$-actin, 5'-TGA GAG GGAAAT CGT GCG TGA C-3' (sense), 5'-GCT CGT TGC CAA TAG TGA TGACC-3' (antisense).

Immunoblot analysis : Nuclear extracts were prepared by using nuclear extract kit (Active Motif, Carlsbad, CA, USA) following the manufacturer's guidelines. To prepare the whole-cell protein extracts, the cells were lysed with sample buffer $(62.5 \mathrm{mM}$ Tris$\mathrm{HCl}, \mathrm{pH} 6.8,2 \% \mathrm{w} / \mathrm{v} \mathrm{SDS}, 10 \%$ glycerol, $50 \mathrm{mM}$ DTT and $0.01 \%$ $\mathrm{w} / \mathrm{v}$ bromophenol blue). The proteins within the cell lysates (30 $\mu \mathrm{g}$ ) were parted using a 10\% SDS-PAGE (sodium dodecyl sulfate-polyacrylamide gel electrophoresis) and were relocated to a nitrocellulose paper. The membrane-blocking treatment reacted with the first main antibody and horse radish peroxidaseconjugated second main antibody, which was used to observe the antibody-specific protein by using an improved chemiluminescence detection system (ECL) (Cell Signaling Technology, USA).

NF-kB reporter assay : A cell suspension of 550,000 RAW-Blue cells $\mathrm{Il}^{-1}$ in fresh growth medium was prepared and $180 \mu$ l of cell suspension was added to each well of a 96 well plate. After the cells were then treated with different doses of $\beta$-glucan for $24 \mathrm{hr}, 150 \mu$ l of QUANTI-Blue solution was added to each well of a 96 well plate followed by $50 \mu$ l of a supernatant from the stimulated RAW-Blue cells. The plate was incubated for $30 \mathrm{~min}$ at $37^{\circ} \mathrm{C}$ and the SEAP levels were determined with a spectrophotometer at $630 \mathrm{~nm}$.

DNA-binding activities of NF-kB subunits : After preparing the nuclear extracts from the cells shown above, the DNA-binding activities of NF-KB p65 or p50 in the nuclear extracts were calculated by utilizing ELISA-based NF-KB transcription factor assay kit (Active Motif), according to the manufacturer's guidelines.

Statistical analysis : Data were expressed as mean \pm standard deviation. Statistical analysis was performed using student's ttest $P<0.05$ considered statistically significant. 


\section{Results and Discussion}

Macrophage cell acts as a main (effector cell on resistance against tumor cells or infective factors through the generation of various types of cytokine and NO. Moreover, it can be self-activated since macrophage exists in various tissues and acts as a body defense mechanism against factors that include inflammatory stimulation (Liew et al., 1997; Ritchlin et al., 2003).

Unlike $\beta$-glucan that has been researched so far, this study used a polycan prototype made by using $\beta-1,3 / 1,6$-glucancentered black yeast $\beta$-glucan developed through the processing of fermented matters and culturing of transmutator in Aureo basidium in glucan. The developed prototype polycan is a complex of biological activity that includes polysaccharide and protein or organic acid and vitamins. To identify the immunity enhancing efficacy of $\beta$-glucan (polycan), RAW264.7 cells were used and measured the changes in the amount of NO, TNF-a, IL$1 \beta$ and IL- 6 generations and their mechanisms.

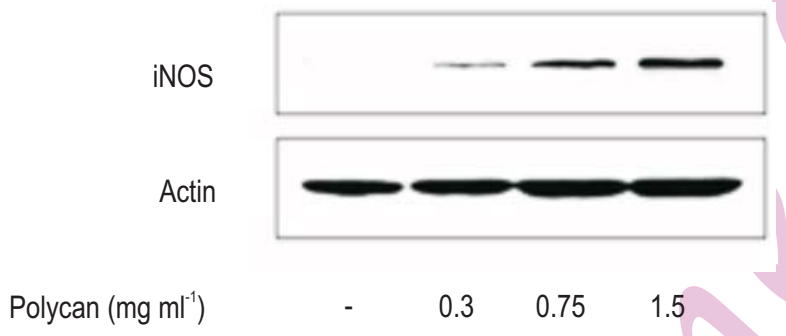

Fig. 2 : Effect of $\beta$-glucan (polycan)on iNOS protein expression in RAW264.7cells

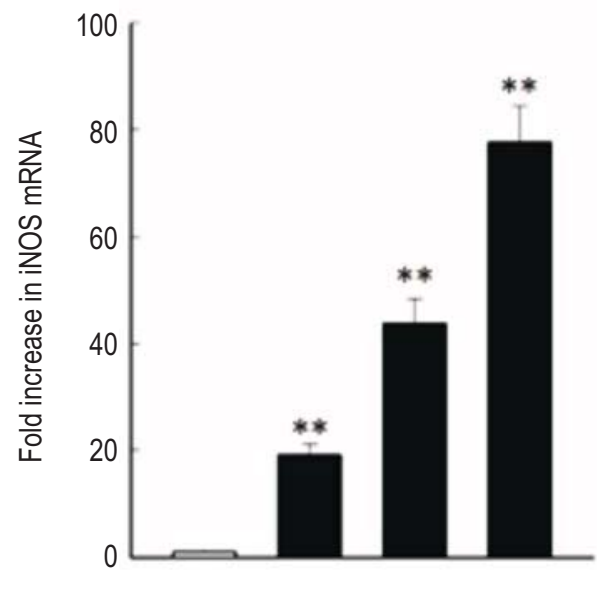

$\begin{array}{lllll}\text { Polycan }\left(\mathrm{mg} \mathrm{ml}^{-1}\right) & - & 0.3 & 0.75 & 1.5\end{array}$

Fig. 3 : Effect of $\beta$-glucan (polycan) on iNOS mRNA expression in RAW264.7 cells. The results are mean \pm S.E.M. of three independent experiments. ${ }^{*} P<0.05$ versus control; ${ }^{* *} P<0.01$ versus control
NO, one of macrophage activation indexes, is a gas molecule produced in L-arginine by NO synthase (NOS) as reactive nitrogen intermediate generated in macrophage cell (Mac Micking et al., 1997). Although excessive NO generation is sometimes harmful to human body by causing tissue damage due to inflammation reaction or vasolidation, an adequate amount of NO has ability to control the microorganisms and cancer cell that triggers infection inside the cells. Therefore, promotion of NO generation can be used as an index to increase the immune function in an appropriate condition that does not cause cytotoxicity (Hibbs et al., 1987; Lorsbach et al., 1993). First, $\beta$ glucan (polycan) was treated in RAW264.7 cells for $24 \mathrm{hr}$ in an adequate concentration and MTT assay was carried out to measure the change of cell survival (Choi et al., 2014). The result showed no significant change in the survival rate of RAW264.7 cells within the concentration range of $\beta$-glucan (polycan) treatment $\left(0.3 \sim 1.5 \mathrm{mg} \mathrm{ml}^{-1}\right)$ investigated in this study (Fig. 1B). Based on this results, $\beta$-glucan (polycan) treatment concentration was set and activation of RAW264.7 cells, according to $\beta$-glucan (polycan), was observed by the change of $\mathrm{NO}$ generation in the supernatant liquid of culture cell. The result demonstrated an immunity enhancing effect through increase of NO generation concentration-dependently within range without cytotoxicity by $\beta$ glucan (polycan) treatment, which was statistically significant increase (Fig. 1A).

To verify whether the increase of $\mathrm{NO}$ generation by $\beta$ glucan (polycan) was due to increase of iNOS expression, the influence of $\beta$-glucan (polycan) on iNOS protein expression was evaluated. According to the experiment result, the non-activated control group that did not add $\beta$-glucan (polycan) did not have

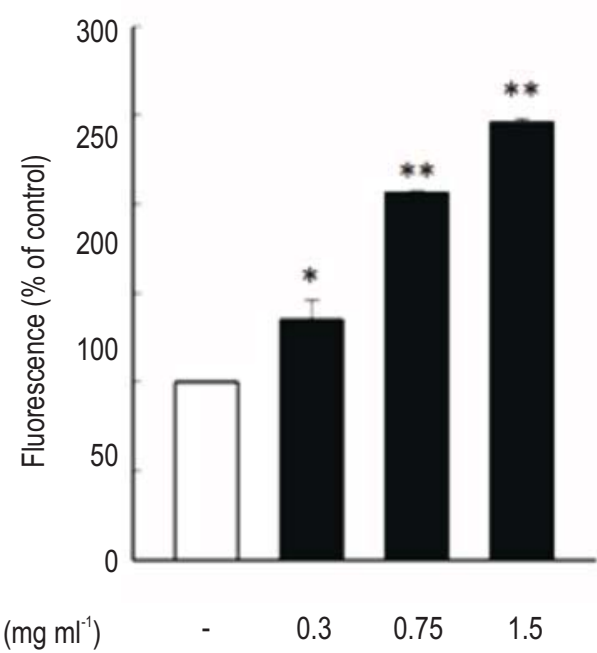

Fig. 4 : Effect of $\beta$-glucan (polycan) on ROS in RAW264.7 cells. The results are mean \pm S.E.M. of three independent experiments. ${ }^{*}<<0.05$ versus control; ${ }^{* *} P<0.01$ versus control 
A

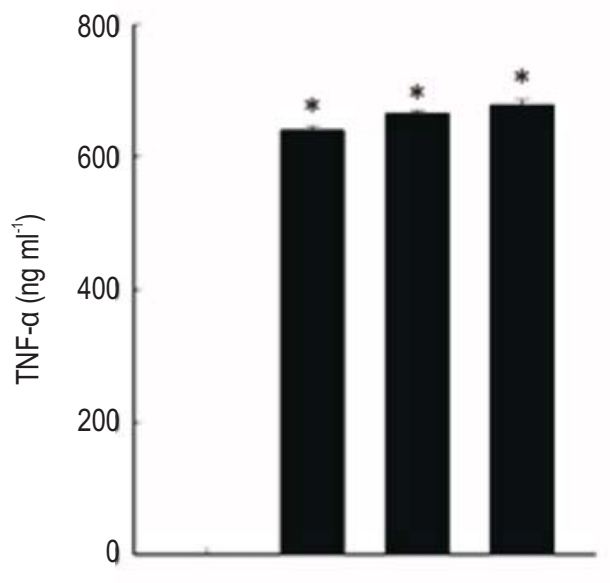

Polycan ( $\left.\mathrm{mg} \mathrm{m}^{-1}\right)$

$0.3 \quad 0.75 \quad 1.5$

B

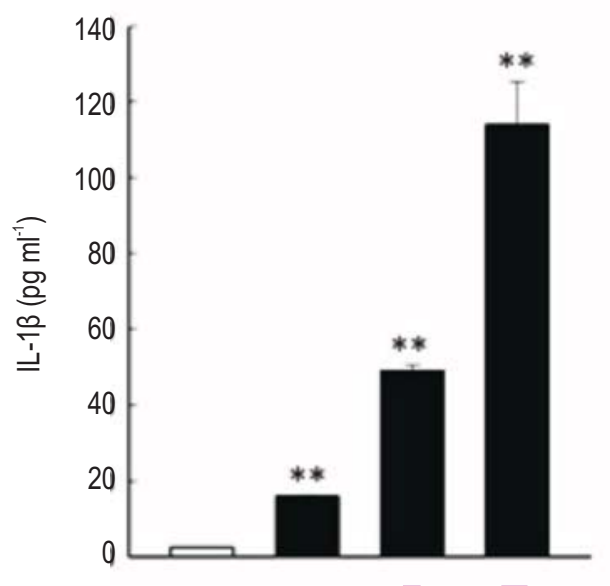

Polycan (mg ml-1)

$\begin{array}{lll}0.3 & 0.75 & 1.5\end{array}$

C

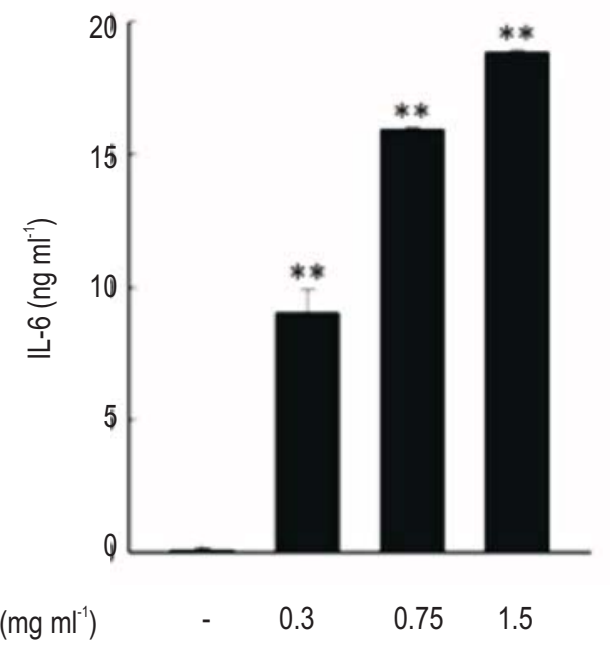

Fig. 5 : Effect of $\beta$-glucan (polycan) on production of TNF- $\alpha(A), I L-1 \beta(B)$ and IL-6 (C) in RAW264.7cells. The results are mean \pm S.E.M. of three independent experiments. ${ }^{*}<<0.05$ versus control; ${ }^{* *} P<0.01$ versus control
A

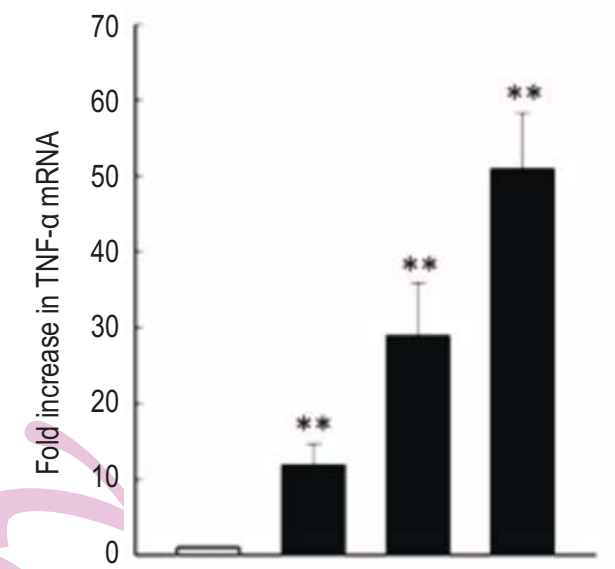

Polycan (mg ml-1)

$0.75 \quad 1.5$

B

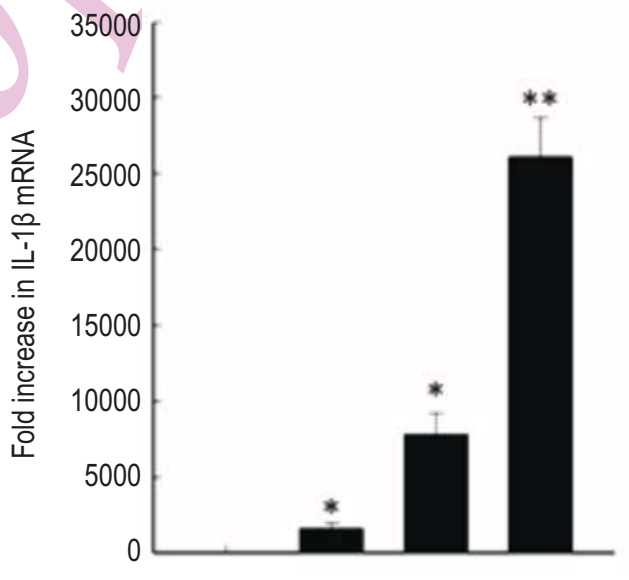

Polycan ( $\mathrm{mg} \mathrm{m}^{-1}$ )

0.3

$0.75 \quad 1.5$

C

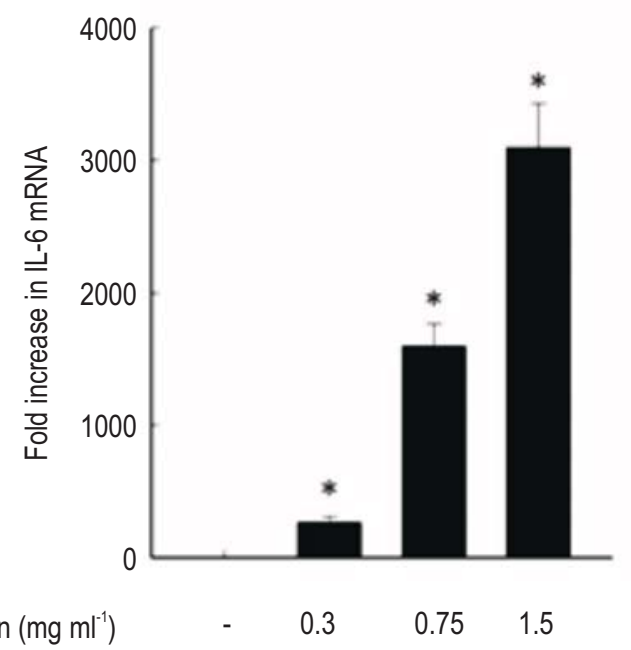

Polycan (mg ml-1)

Fig. 6 : Effect of $\beta$-glucan (polycan) on TNF- $\alpha$ (A), IL-1 1 , (B) and IL-6(C) mRNA expression in RAW264.7cells. The results are mean \pm S.E.M. of three independent experiments. ${ }^{*} P<0.05$ versus control; ${ }^{* *} P<0.01$ versus control 


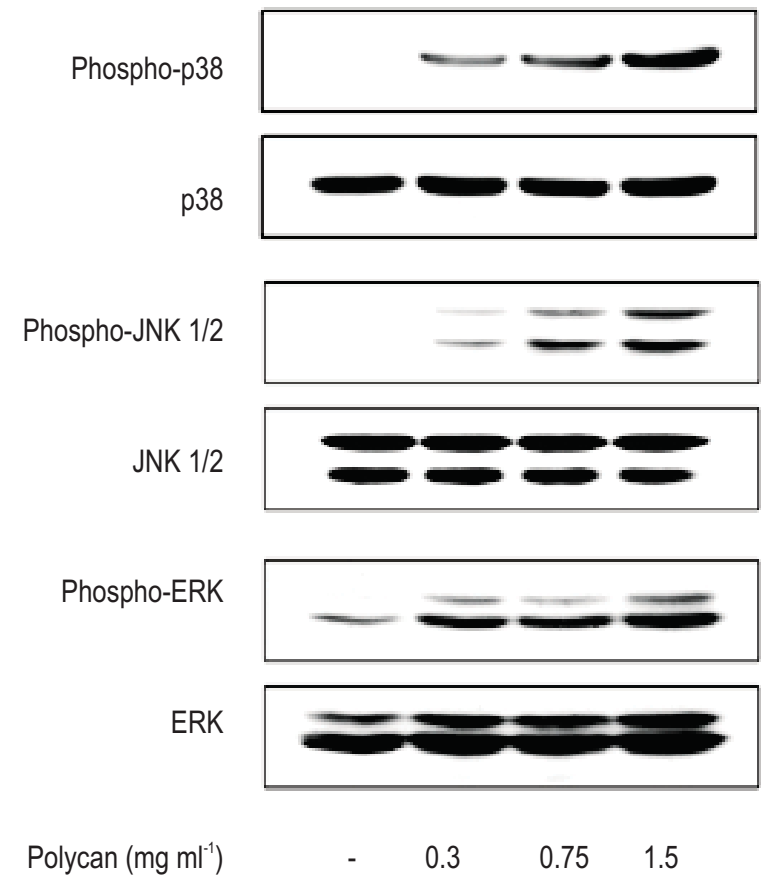

Fig. 7 : Effect of $\beta$-glucan (polycan) on phosphorylation of p38, JNK and ERK in RAW264.7cells

iNOS protein expression, but the experiment group activated by $\beta$-glucan (polycan) had an expression of about $130 \mathrm{kDa}$ protein that reacts with specific antibody on iNOS. Additionally, it was observed that the increasing concentration of $\beta$-glucan (polycan)led to increase of the iNOS protein expression in the same way as increase in NO generation (Fig. 2). Also, the effect of $\beta$-glucan (polycan) on iNOS and iNOS mRNA expression was confirmed through Real Time PCR. When RAW264.7 cells were exposed to $\beta$-glucan (polycan), iNOS mRNA was expressed (Fig. $3)$. These consequences showed that the increase in NO generation was due to increase of the iNOS expression in the macrophage cell on $\beta$-glucan (polycan).

Reactive oxygen species (ROS) are oxygen compound with free electrons; if they are increased excessively like NO, their anti-oxidation defense mechanism is reduced and oxidation damage is caused, destroying tissues and bringing oxidation stress as well as various pathological changes such as inflammation, aging or cancer. However, an adequate amount of ROS has an immunity activity of expelling bacteria or virus. In this study carried out to measure the generation of intracellular ROS in RAW264.7 cells treated with $\beta$-glucan (polycan) using fluorescence-activated cell sorting analysis. The level of intracellular ROS increased concentration-dependently by $\beta$-glucan (polycan) and was 2.5 times higher than the control value in high concentration (Fig. 4). $\beta$ glucan (polycan) showed an immunity enhancing effect by promoting ROS generation as in NO generation.
Among various cytokine, TNF- $a$ is an important factor for immunity cell modulation. It is a kind of signal molecule widely involved in the innate immune response which induces the suicide signal on cancer cell or inhibits the duplication of virus inside a cell. TNF-a is mainly secreted from an activated macrophage cell but is also secreted from various other cells such as helper T-cell and natural killer cell (Locksley et al., 2001). Also, IL-1, which was known as an endogenous heating cytokine at first, consists of IL-1 $\alpha$ and IL- $1 \beta$ that are expressed by different genes. IL-1 $\beta$ is especially a cytokine modulating inflammatory and immune reactions on infection and plays a key role in inflammation and host defense (Lane and Lachmann, 2011; Wang et al., 2010). IL-6 is a cytokine of $26 \mathrm{kDa}$ occurring from monocytes, macrophage cells, T and B lymphocytes and some other cells, and have a variety of functions in immune-activity, infection and inflammatory reaction. Cytokine has the aspects of both immunity inhibition and immuno-facilitation in terms of biological activity. Its adequate, not excessive, generation makes the signal transfer that induces the starting of the macrophage cell work as a mediating cytokine and may be utilized as an index to forecast the beginning of macrophage by some stimulation. According to the research 3 cytokines of TNF- $\alpha$, IL-1 $\beta$ and IL- 6 had increased generation in RAW264.7 cells (Fig. 5), due to the increased expression of each cytokine at mRNA level (Fig. 6). This is considered that the added creation of NO, TNF- $\alpha, I L-1 \beta$ and IL- 6 was accompanied in macrophage cell activation by $\beta$-glucan (polycan).

MAPKs signal pathway that includes extracellular signalregulated kinase (ERK), c-Jun amino terminal kinase (JNK), and p38 mediates important signal transfer reaction of immunity and inflammatory system, and acts as the main factor for generation and modulation of various biological functions of cell activity substance including macrophage (Arthur and Ley, 2013; Ivashkiv, 2011). To comprehend the part played by signal transfer system in the cell that is involved in immunomodulation reaction by $\beta$ glucan, the study researched activation of ERK, JNK and p38 MAPK, the 3 kinases belonging to MAPKs.By the $\beta$-glucan (polycan) treatment, the MAPK that contains p38, JNK, and ERK was phosphorylated. For JNK, phosphorylation increased reliantly on the concentration of $\beta$-glucan (polycan), and p38 and ERK had the starting of phosphorylation from low concentration (Fig. 7). According to the study result, $\beta$-glucan(polycan) stimulates the activity of three MAPKs: ERK, JNK, and p38, showing that MAPK pathway plays an important role in the generation of NO, TNF-a, IL-1 $\beta$ and IL- 6 by $\beta$-glucan(polycan).

The activity of certain proteins related with the signal modulation in cells play a role as a very important modulator for the activity of macrophage cell (Medzhitov and Janeway, 2000; Zhou et al., 2014). Among them, NF-KB acts as a core transcription modulator in the transcription of immunomodulation genes that include iNOS and cytokine. In general, NF-kB exists in cytoplasm by forming the inhibitor of NF-KB (IKB) protein and complex. However, if it reacts to immuno-activity stimulation and 


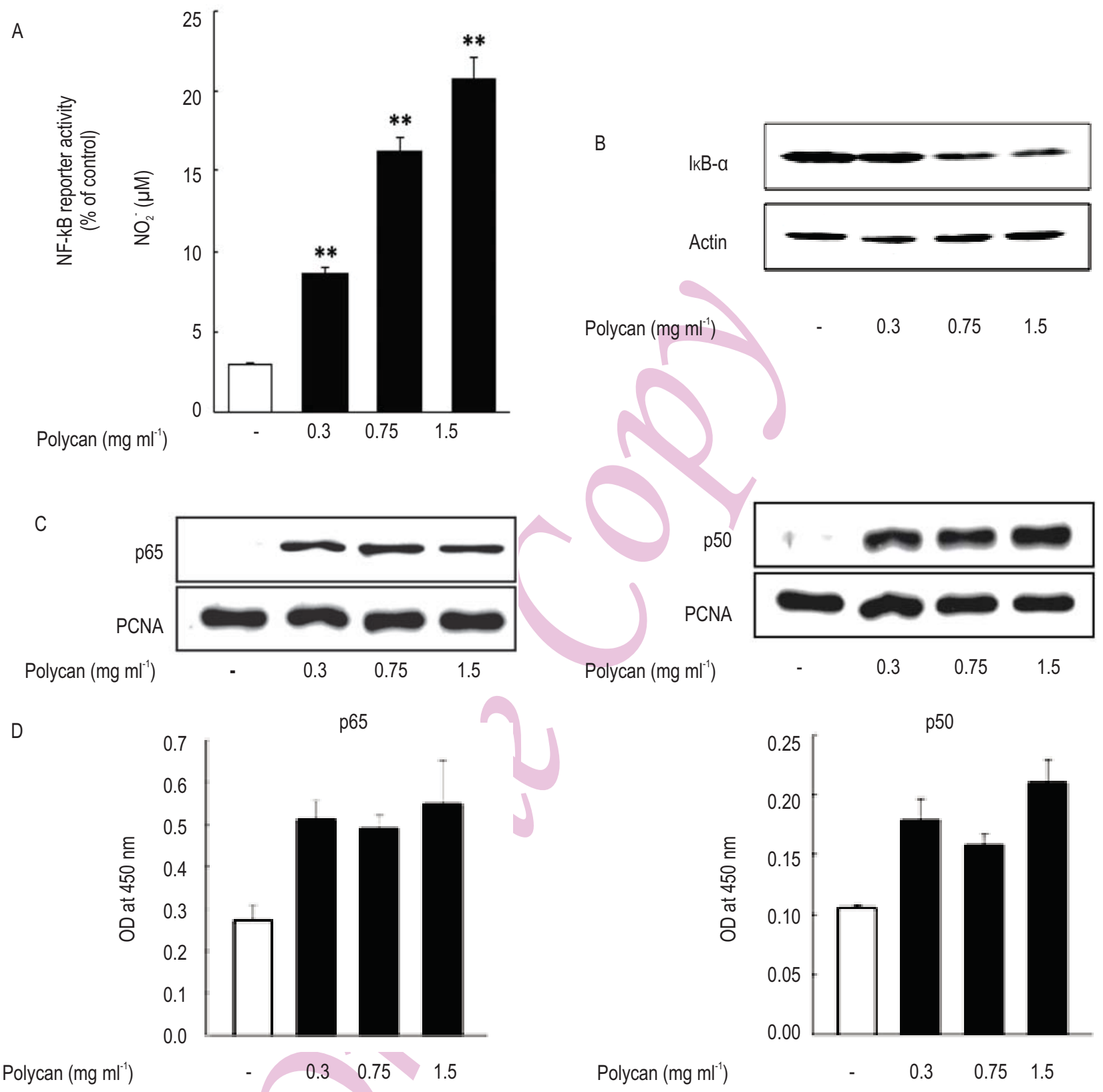

Fig. 8 : Effect of $\beta$-glucan (polycan) on activation of NF-kB in RAW264.7cells, (A) Activity of SAEP released from RAW-BlueTM cells, (B) IkB-a degradation, (C) Nuclear translocation of NF-kBp65 and p50 and (D) DNA-binding activities of NF-kB p65 and p50

is decomposed through ubiquitin-proteasome pathway after phosphorylation of IKB, NF-KB is isolated, trans locates into the nucleus, and activates the domain of immune-modulation genespecific promoter (Gasparini and Feldmann, 2012; Hayden and Ghosh, 2014). Therefore, the study researched the influence on the increase of NF-KB activity in immuno modulation reaction by $\beta$-glucan (polycan). First, study performed SEAP assay using RAW-blue cell to figure out whether $\beta$-glucan(polycan) increases $\mathrm{NF}-\mathrm{KB}$ transcriptional activity. NF-KB transcriptional activity in
RAW-blue cell that treated $\beta$-glucan (polycan) for $24 \mathrm{hr}$ increased by 15 times compared to the control group. (Fig. 8A). In addition, the cytoplasmic level of $\mathrm{IKB}$ - $\mathrm{a}$ protein was measured by immuneblot analysis to check if $\beta$-glucan (polycan) would influence IKB- $\alpha$ degradation, the upstream signaling pathway of NF-KB. In the result, a noticeable degradation of IKB- $a$ was observed in the cell that treated $\beta$-glucan(polycan) (Fig. 8B). Next, the study examined whether $\beta$-glucan (polycan) influenced the nuclear translocation of NF-KB p65 and p50, the downstream of IKB- $\alpha$ 


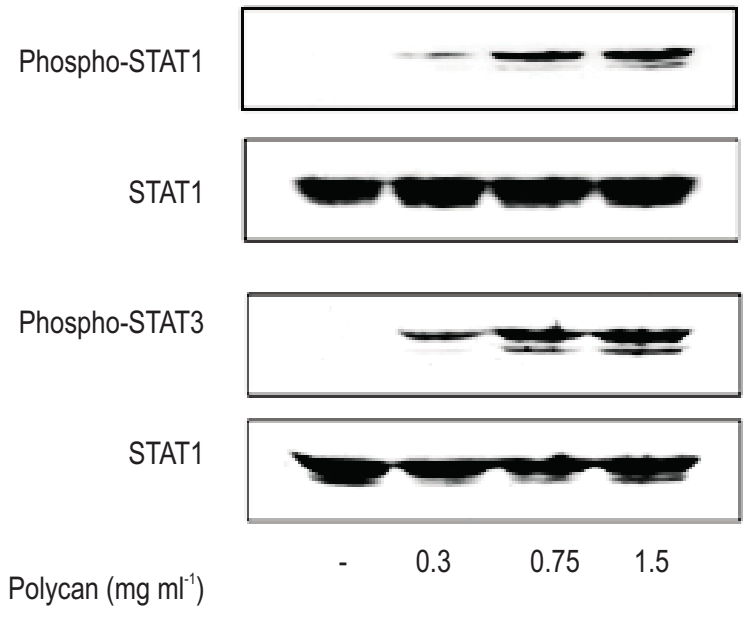

Fig. 9 : Effect of $\beta$-glucan (polycan) on phosphorylation of STAT1 and STAT3 in RAW264.7 cells

degradation. Nuclear fractions were prepared and an immuneblot analysis was carried out using an antibody on NF-kB p65 and p50. B-glucan (polycan) markedly induced the nuclear translocation of NF-KB subunits (Fig. $8 \mathrm{C}$ ). Lastly, the study checked whether $\beta$-glucan (polycan) could have an influence on the transcription that relies on NF-KB by beginning of union of DNA and NF-KB. The DNA union action of NF-KB in the nucleus was analyzed utilizing the ELISA-based NF-KB p65/NF-KB p50 transcription factor assay kits. The DNA union activity of NF-KB p65 and p50 increased markedly by $\beta$-glucan (polycan) (Fig. 8D).

Signal transducer and activator of transcription (STAT) is another main transcription factor that has been suggested by the immune reactions (Pfitzner et al., 2004). Among seven mammalian STAT family members, STAT1 and STAT3 are the main modulators of the expression mediating substances of various immune reactions in activation macrophage cells (Gao et al., 1998; Samavati et al., 2009). In this study, it was also examined as to whether the NO, TNF- $\alpha, I L-1 \beta$ and IL- 6 generations induced by $\beta$-glucan (polycan) were related with the beginning of STAT1 and STAT3 pathways. Immuno-blot was carried out by preparing cell lysates and by using the antibody against phospho-STAT1 and phospho-STAT3. $\beta$-glucan (polycan) took part in the STAT1 and STAT3 pathway activations by increasing the STAT1 and STAT3 phosphorylation in RAW264.7 cells (Fig. 9).

Overall, the results the current study indicate that $\beta$ glucan induces production of iNOS-derived NO, TNF- $\alpha$, IL-1 $\beta$ and IL-6 in murine macrophages through induction of MAPK, NF$\mathrm{KB}$, STAT1 and STAT3 activation. Therefore, the results of this study indicate $\beta$-glucan has high possibility to be developed as an immunity enhancement through macrophage cell activation.

\section{Acknowledgments}

This research was performed with the support of the Industry Core Technology Development Project (No. 10049026 and 10063302), Ministry of Trade, Industry and Energy, Korea.

\section{References}

Arthur, J.S. and S.C.Ley: Mitogen-activated proteinkinases in innate immunity.Nat. Rev. Immunol., 13, 679-692 (2013).

Babineau, T.J., P. Marcello, W. Swails, A. Kenler, B. Bistrian and R.A. Forse: Randomised phasel/II trial of a macrophage-specific immunomodulatory(PGG-Glucan) in high-risk surgical patients.Ann. Surg., 220, 601-609 (1994).

Beutler, B.: Innate immunity: An overview. Mol. Immunol., 40, 845-859 (2004).

Choi, J.S., B.B. Lee, K.H. Do, H.J. Bae, J.H. Sohn, K.K. Cho and I.S. Choi: Effects of $Y$-irradiation on the color and biological activity of ethanol extracts of the brown seaweed Ecklonia cava. J. Environ. Bol., 35, 179-187 (2014).

Compton, R., D. Williams and W. Browder: The beneficial effect of enhanced macrophage function on the healing of bowel anastomoses. Am. Surgen., 62, 14-18 (1996).

Gao, J.J., M.B. Filla, M.J. Fultz, S.N. Vogel, S.W. Russell and W.J. Murphy: Autocrine/paracrine IFN-a $\beta$ mediates the lipopolysaccharide-induced activation of transcription factor Stat1a in mouse macrophages: Pivotal role of Stat1a in induction of the inducible nitric oxide synthase gene. J. Immunol., 161, 48034810 (1998).

Gasparini, C. and M. Feldmann: NF-KB as a targetfor modulating inflammatory responses. Curr. Pharm. Des., 18, 5735-5745 (2012).

Green, L.C., D.A. Wagner, J. Glogowski, P.L. Skipper, J.S. Wishnok and S.R. Tannenbaum: Analysis of nitrate, nitrite, and [15N] nitrate in biological fluids. Anal. Biochem., 126, 131-138 (1982).

Hamada, N., K. Deguchi, T. Ohmoto, K. Sakai, T. Ohe and H. Yoshizumi: Ascorbic acid stimulation of production of a highly branched, beta1,3-glucan by Aureobasidium pullulans K-1--oxalic acid, a metabolite of ascorbic acid as the stimulating substance. Biosci. Biotechnol. Biochem., 64, 1801-1806 (2000).

Hayden, M.S. and S. Ghosh: Regulation of NF-kB byTNF family cytokines. Semin. Immunol., 26, 253-266 (2014).

Hibbs, J.B., R.R. Taintor and Z. Vavrin: Macrophage cytotoxicity: Role for L-arginine deiminase and imino nitrogen oxidation to nitrite. Science, 235, 473-479 (1987).

Ivashkiv, L.B.: Inflammatory signaling in macrophages: Transitions from acute to tolerant and alternative activationstates. Eur. J. Immunol., 41, 2477-2481 (2011).

Kayser, O., K.N. Masihi and A.F. Kiderlen: Natural products and synthetic compounds as immunomodulators. Expert. Rev. Anti-Infect. Ther., 1, 319-335 (2003).

Klimp, A.H., E.G. de Vries, G.L. Scherphof and T. Daemen: A potential role of macrophage activation in thetreatment of cancer. Crit. Rev. Oncol. Hematol., 44, 143-161 (2002).

Lane, T. and H.J. Lachmann: The emerging role of interleukin-1 $\beta$ in autoinflammatory diseases.Curr. Allergy Asthma Rep., 11, 361368 (2011).

Leathers, T.D.: Biotechnological production and applications of pullul an. Appl. Microbiol. Biotechnol., 62, 468-473 (2003). 
Lee, J.S. and E.K. Hong: Immunostimulating activityof the polysaccharides isolated from Cordyceps militaris. Int. Immunopharmacol., 11, 1226-1233 (2011).

Liew, F.Y., X.Q. Wei and L. Proudfoot: Cytokinesand nitric oxide as effector molecules against parasiticinfections. Philos. Trans. $R$. Soc. Lond. B. Biol. Sci., 352, 1311-1315(1997).

Liles, W.C.: Immunomodulatory approaches to augment phagocytemediated host defense for treatment of infectious diseases. Semin. Respir. Infect.,16, 11-17 (2001).

Locksley, R.M., N. Killeen and M.J. Lenardo: The TNF and TNF receptor super families: Integrating mammalian biology. Cell, 104, 487-501 (2001).

Lorsbach, R.B., W.J. Murphy, C.J. Lowenstein, S.H. Snyder and S.W. Russell: Expression of the nitric oxidesynthase gene in mouse macrophages activated for tumor cell killing. Molecular basis for the synergy between interferon-gamma and lipo polysaccharide. J. Biol. Chem., 268,1908-1913 (1993).

MacMicking, J., Q.W. Xie and C. Nathan: Nitric oxide and macrophage function. Annu. Rev. Immunol., 15, 323-550 (1997).

Mahauthman, R., C.J. Howell, B.W. Spur, L.J. Youlten, T.J. Clark, M.H. Lessof and T.H. Lee: The generation and cellular distribution of leukotriene $\mathrm{C} 4$ in human eosinophils stimulated by unopsonised zymosan and glucan particles. J. Allergy Clin. Immunol., 81, 696705 (1998).

Medzhitov, R. and C. Janeway: Innate immune recognition: Mechanisms and pathways. Immunol. Rev., 173, 89-97 (2000).

Moriya, N., Y. Maurya, H. Nomura, K. Kusano, Y. Asada, H. Uchiyama, E.Y. Park and M. Okabe : Improved beta-glucan yield using an Aureobasidium pullulans M-2 mutant strain in a 200-L pilot scale fermentor targeting industrial mass production. Biotechnol. Bioprocess Eng.,18, 1083-1089 (2013).

Murray, P.J. and T.A. Wynn: Protective and pathogenic functions of macrophage subsets. Nat. Rev. Immunol., 11, 723-737 (2011).

Ono, N., N.N. Miura, N. Chiba, Y. Adachi and T. Yadomae: Comparison of the immuno pharmacological activities of triple and single-helical schizophylian in mice. Bio. Pharm.,18, 1242-1247 (1995).

Pfitzner, E., S. Kliem, D. Baus and C.M. Litterst: The role of STATs in inflammation and inflammatory diseases. Curr. Pharm. Des., 10, 2839-2850 (2004).

Pinto, M.R., D. Melillo, S. Giacomelli, G. Sfyroera and J.D. Lambris: Ancient origin of the complement system: Emerging invertebrate models. Adv. Exp. Med. Biol., 598,372-388 (2007).

Ritchlin, C.T., S.A. Haas-Smith, P. Li, D.G. Hicks and E.M. Schwarz: Mechanisms of TNF-alpha- and RANKL-mediated osteoclastogenesis and bone resorption in psoriatic arthritis. J. Clin. Invest., 111, 821-831 (2003).

Samavati, L., R. Rastogi, W. Du, M. Hüttemann, A. Fite and L. Franchi: STAT3 tyrosine phosphorylation is critical for interleukin 1 beta and interleukin-6 production in response to lipopolysaccharide and live bacteria. Mol. Immunol., 46, 1867-1877 (2009).

Seo, H.P., J.M. Kim, H.D. Shin, T.K. Kim, H.J. Chang, B.R. Park and J.W. Lee: Production of beta-1,3/1,6-glucan by Aureobasidium pullulans SM-2001. Korean J. Biotechnol. Bioeng., 17, 376-380 (2002).

Thornton, B.P., V. Vetvicka, M. Pitman, R.C. Gold man and G.D. Ross: Analysis of the sugar specificity and molecular location of $\beta$ glucan-binding lectin site of complement receptor type 3 (CD11b/CD18). J. Immunol., 156, 1235-1246 (1996).

Wang, D., S. Zhang, L. Li, X. Liu, K. Mei and X. Wang: Structural insights into the assembly and activationof IL-1 $\beta$ with its receptors. Nat. Immunol., 11, 905-911 (2010).

Wolf, S.F., D. Sieburth and J. Sypek: Interleuk in 12: A key modulator of immune function. Stem Cell, 12, 154-168 (1994).

Zhou, D., C. Huang, Z. Lin, S. Zhan, L. Kong, C. Fang and J. Li: Macrophage polarization and function with emphasis on the evolving roles of coordinated regulation of cellular signaling pathways. Cell Signal, 26, 192-197 (2014). 